\title{
О чем говорит отклонение от закона Ципфа?
}

Е.А. КОЛОМАК, доктор экономических наук, Институт экономики и организации промышленного производства СО РАН, Новосибирск. E-mail: ekolomak@academ.org

В статье обсуждается связь закона Ципфа с механизмами управления развитием городской системы и оценивается влияние единиц наблюдения и размера выборки на отклонение распределения от предписываемых параметров. Работа опирается на сравнение оценок коэффициентов Ципфа и распределений для разных периодов и при различных подходах к определению города. Делается вывод о том, что отклонение от правила «ранг - размер» зависит от размера и объектов выборки, при этом его неверно трактовать как дефект структуры городской системы и снижение экономической эффективности.

Ключевые слова: город, городская агломерация, закон Ципфа, экономическая эффективность

Рост роли городов в экономической и социальной жизни стран и регионов инициировал исследовательский интерес к изучению законов и тенденций развития городов и городских систем. Одной из таких выявленных закономерностей является закон Ципфа, или закон «ранг - размер», который связывает численность населения города с его местом в упорядоченном по убыванию размера списке городов. Ученый, чьим именем назвали данный закон, был не экономистом и не географом, а лингвистом, и данная регулярность была им выявлена в отношении словоупотребления. Джордж Ципф заметил, что самое популярное слово использовалось в речи в два раза чаще, чем второе по частоте употребления, в три раза чаще, чем слово третьего ранга, в четыре раза чаще, чем слово четвертого ранга, и т. д.

Эмпирические исследования городских поселений, построение иерархических и упорядоченных схем для городских систем привели к заключению, что правило, обнаруженное в лингвистике, работает и в отношении распределения городского населения [1]. Самый крупный город во многих странах оказывается примерно в два раза больше по численности населения второго по размеру города, в три раза больше третьего города в упорядоченном списке и т. д. Для демонстрации этого утверждения в таблице приведена статистика по некоторым странам. 
Численность населения крупнейших городов

некоторых стран мира, тыс. чел.

\begin{tabular}{|l|c|c|c|c|}
\hline \multirow{2}{*}{ Страна } & \multicolumn{4}{|c|}{ Численность населения в городах } \\
\cline { 2 - 5 } & 1-го ранга & 2-го ранга & 3-го ранга & 4-го ранга \\
\hline \multirow{2}{*}{ США } & Нью-Йорк, & Лос-Анжелес, & Чикаго, & Хьюстон, \\
& 8491 & 3929 & 2722 & 2240 \\
\hline \multirow{2}{*}{ Канада } & Торонто, & Монреаль, & Калгари, & Оттава, \\
& 2503 & 1620 & 988 & 812 \\
\hline \multirow{2}{*}{ Франция } & Париж, & Марсель, & Лион, & Тулуза, \\
& 2250 & 851 & 491 & 447 \\
\hline \multirow{2}{*}{ Испания } & Мадрид, & Барселона, & Валенсия, & Севилья, \\
& 3234 & 1620 & 797 & 702 \\
\hline \multirow{2}{*}{ Италия } & Рим, & Милан, & Неаполь, & Турин, \\
& 2641 & 1246 & 9601 & 872 \\
\hline \multirow{2}{*}{ Япония } & Токио, & Йокогама, & Осака, & Нагоя, \\
& 8979 & 3690 & 2666 & 2264 \\
\hline
\end{tabular}

Эмпирическим же путем было получено еще несколько результатов: во-первых, закон Ципфа хорошо работает в предсказании размера крупнейших городов и мегаполисов, но плохо - для средних и малых городов с численностью населения менее 100 тыс. чел. Вторым выводом стало то, что закон неплохо описывает городскую систему отдельной страны, но дает неудовлетворительные результаты при попытках его тестирования как на материале межгосударственных объединений и союзов, так и для отдельных регионов страны [2]. Это позволило предположить, что правило «ранг - размер» поддерживается тесными социальными связями и разделением экономических и административных функций между городами, которые более четко определены в рамках отдельной страны в целом.

Наконец, еще одно наблюдение было связано с различиями между западными странами с рыночной экономикой и социалистическими странами: последние имели крупнейшие города существенно меньше, чем предсказывал закон Ципфа, в отличие от рыночных стран [3]. Это объяснялось политикой сглаживания пространственных различий и сдерживанием миграции в крупные города в социалистических странах [4]. Централизованное управление критиковалось за то, что в экономике недоиспользовался агломерационный потенциал, это тормозило развитие и снижало экономические результаты $[5,6]$. Считалось, что политика социалистических стран, направленная на сглаживание пространственных различий, нарушала естественные пропорции городской системы, зафиксированные в законе Ципфа. Таким образом, правило «ранг размер» ассоциировалось с рыночным механизмом и с более эффективной пространственной организацией, отклонение же от этой закономерности трактовалось как дефекты пространственной структуры и связывалось с экономическими потерями.

\section{Закон Ципфа и рынок}

Пространственную политику советской России, как и многих стран Восточной Европы, критиковали за то, что размеры их крупнейших городов существенно отклоняются вниз от предсказаний закона Ципфа. Утверждалось, что численность населения Москвы, Санкт-Петербурга, а также 12 других городов России первых рангов «слишком мала», и это является результатом неоправданного сдерживания миграции в эти города.

Переход к рыночной экономике, упразднение системы прописки и значительное сокращение участия государства в регулировании территориального размещения экономической активности в России должны были, по прогнозам, высказанным в начале реформ, привести к стремительному росту больших городов. И как результат городская система страны должна была продемонстрировать конвергенцию к параметрам закона Ципфа. Для тестирования данного утверждения будем использовать функцию распределения, а также формальную интерпретацию этого правила, последнее опирается на оценку регрессии $\ln \mathrm{R}_{\mathrm{i}}=\alpha-\beta \ln \mathrm{S}_{\mathrm{i}}+\varepsilon_{\mathrm{i}}$, где $\mathrm{R}_{\mathrm{i}}-$ логарифм порядкового номера или ранга в упорядоченной по убыванию размера последовательности, $\mathrm{S}_{\mathrm{i}}$ - логарифм численности населения города, $\varepsilon_{\mathrm{i}}$ - ошибка оценивания. В случае полного соответствия закону Ципфа, коэффициент регрессии $\beta$ равен 1 . При этом отклонение от линии регрессии вверх говорит о том, что размер города больше предсказанного правилом, а отклонение вниз является показателем того, что город «слишком мал».

Сравним изменения в характеристиках распределения Ципфа для российских городов с начала переходного периода до последних лет (рис. 1). Источником данных о численности населения городов являлась база «Экономика городов России» (один из ресурсов портала «Мультистат»), в ней представлены данные по более 1000 городам страны, которые охватывают свыше 90\% городского населения. В базе отсутствует информация по поселкам городского типа, население которых учитывается как городское, по закрытым территориальным образованиям, а также по некоторым малым 
городам. Такую выборку можно считать репрезентативной, в ней представлены все крупные и средние города, а именно эта часть распределения представляет интерес для исследования.

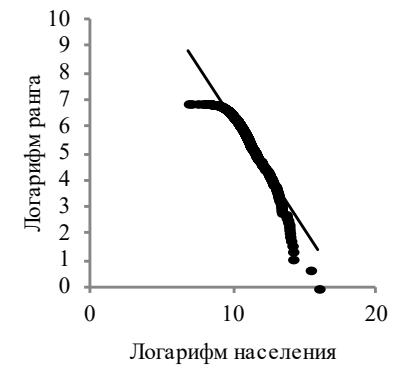

1991 г.

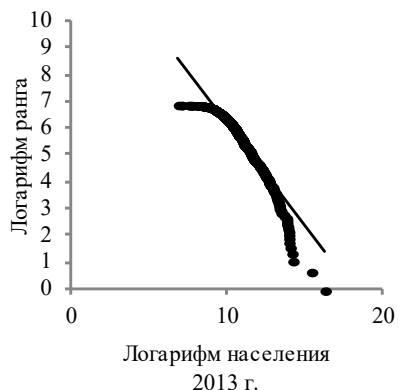

2013 г.
Рис. 1. Закон Ципфа и определение города

Из графика, представляющего распределение для 1991 г., видно, что, действительно, точки, соответствующие крупнейшим городам России, лежат заметно ниже линии регрессии, из чего следует, что их размер в конце периода централизованного планирования - меньше прогнозов закона Ципфа. Однако за годы рыночных реформ предсказанных изменений в форме распределения не произошло, более динамичного роста городов первых рангов и приближения правых нижних точек к выравнивающей линии не наблюдается. Не произошло и сближения коэффициента регрессии с теоретическим значением, он, наоборот, отклонился еще дальше и снизился с 0,814 до 0,760 . Это означает, что распределение городского населения было и остается более неравномерным, чем должно быть в соответствии с правилом «рангразмер», и неоднородность за переходный период выросла.

В результате напрашиваются два предположения: либо закон Ципфа неверно связывать с рыночным механизмом формирования пропорций городской системы, либо предсказания эффектов рыночных реформ для России были ошибочными.

Заметное отклонение от линии регрессии (см. рис. 1) наряду с крупными городами (нижняя правая часть графика) имеют и малые города, относящиеся к высокому рангу (верхняя левая часть графика). В случае малых городов отклонение можно объяснить тем, что в России есть много населенных пунктов, которые имеют статус города, хотя численность их населения небольшая и не отвечает формальным требованиям, предъявляемым к городскому поселению*.

В построении распределения, представленного на рисунке 1 , участвовали все населенные пункты из базы данных, имеющие статус города. Данный факт может влиять на угол наклона линии регрессии, так как используется метод наименьших квадратов, и отклонение наблюдений, относящихся к малым городам, тянет прямую влево, делая ее менее крутой. Это приводит к снижению коэффициента регрессии и удалению точек, соответствующих крупнейшим городам, от выравнивающей линии. Оценим, насколько существенно влияние статистического фактора на полученные результаты, исключив те города, которые не отвечают официальному критерию размера и имеют численность населения менее 12 тыс. чел. (рис. 2).

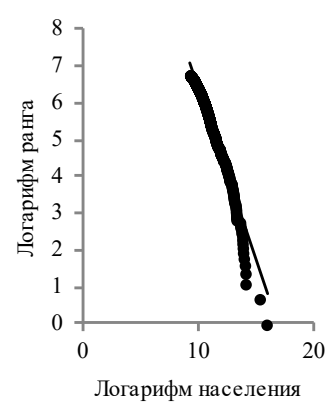

1991 г.

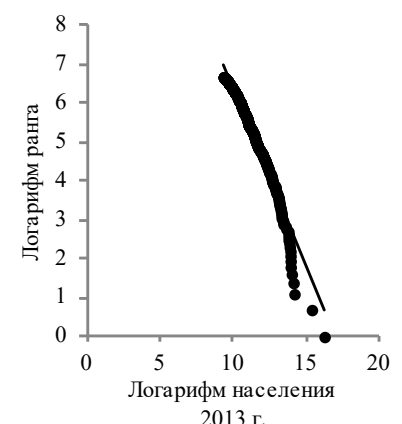

2013 г.
Рис. 2. Город или городская агломерация?

Исключение малых городов из выборки улучшило картину с точки зрения соответствия закону Ципфа. Большая часть точек распределения лежит на выравнивающей прямой, коэффициент регрессии приблизился к 1, он равен 0,938 для 1991 г. и 0,904 для 2013 г. Однако точки, представляющие крупнейшие города страны, хотя и приближаются к линии, но остаются лежать ниже нее. Итог состоит в следующем: графики распределения Ципфа

\footnotetext{
* По российскому законодательству населенный пункт может получить городской статус, если численность его населения превышает 12 тыс. чел., ине более $15 \%$ его жителей заняты в сельскохозяйственном производстве. Но в России есть много малых городов (около 20\%), где число жителей меньше 12 тыс. чел., есть даже города с численностью населения чуть больше 1 тыс. чел.
} 
и выводы, основанные на них, зависят от определения города, от методик официальной статистики и от выборки, на которой делаются расчеты.

Заключения, основанные на распределении Ципфа, могут быть также чувствительными к географическим границам городских поселений. Большая часть оценок, полученных для западных стран, использует в качестве единиц анализа городские агломерации, в то время как в России ведется статистика по городам, а не по агломерациям. Переход к данным по агломерациям вместо городов должен затронуть, главным образом, крупнейшие города страны, увеличив их население и сдвинув точки ближе к требуемому законом значению.

В России не только не ведется официальной статистики по городским агломерациям, но и отсутствует ее однозначное определение. Для изучения влияния на распределение Ципфа выбора в качестве единицы наблюдения городских агломераций были привлечены оценки Г.М. Лаппо и соавторов, сделанные для 2007 г. [7].

Сравнение распределений для городов и городских агломераций представлено на рис. 3. Смена объектов наблюдения практически не повлияла на качественную картину распределения, вывод об отставании размеров крупнейших городов сохраняется. Но коэффициент регрессии различается, по выборке городов он равен 0,918 , а для агломераций - 0,877. Таким образом, переход к агломерациям меняет вывод об уровне неоднородности городской системы, в случае агломераций он оказывается выше.

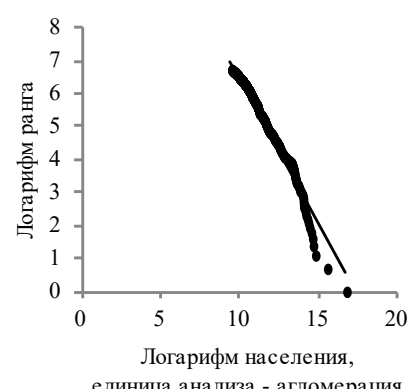

единица анализа - агломерация

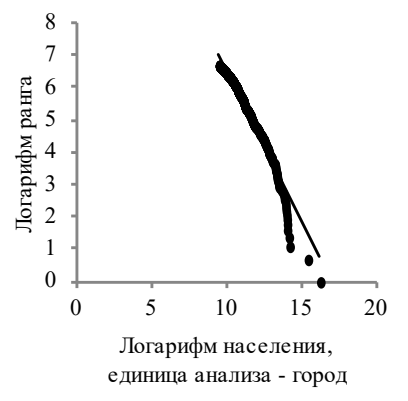

единица анализа - город
Рис. 3. Сравнение распределений для городов и городских агломераций

\section{Закон Ципфа и экономическая эффективность}

Формулировка закона Ципфа для городских систем опирается на эмпирические наблюдения. Предположение о его связи с работой рыночных механизмов также является выводом, который не нашел пока теоретического доказательства и исходит из того факта, что с большей точностью предсказываются размеры крупных городов западных стран с рыночной экономикой, чем для городов стран с централизованным планированием.

Единственным известным теоретическим обоснованием правила «ранг - размер» является результат, полученный с использованием гипотез о стохастических свойствах процесса развития городской системы $[8,9]$. В работах доказывается: при предположении, что темп роста города - случайная величина, имеющая постоянное среднее значение и неизменную дисперсию, в пределе распределение размера городов будет иметь свойства, отвечающие закону Ципфа. Но до сих пор не предложено теоретической модели, включающей описание механизма распределения экономической активности или критерий экономической эффективности, которые бы гарантировали свойства равновесия, приводящие к правилу «ранг - размер» в распределении городского населения.

Поэтому связывать закон Ципфа с подходами в управлении экономикой и делать заключения о более предпочтительной структуре городской системы, подразумевая критерий экономической эффективности, представляется некорректным. Во-первых, существует много примеров провалов рынка именно в сфере размещения производств: умирающие города, депрессивные районы, большие пространственные различия. Во-вторых, в западных странах, которые подтверждают хорошую предсказательную способность закона Ципфа, государственное вмешательство и регулирование особенно активно используются в решении проблем территориального и городского развития. Такими примерами являются реализация крупных инфраструктурных проектов, градостроительные стандарты, зонирование территорий и др.

Подводя итог, можно сказать, что использование закона Ципфа в качестве эталона структуры городской системы не имеет достаточно убедительных аргументов. Связь этой закономерности ни с рыночными механизмами регулирования, ни с какимлибо экономическим критерием оптимальности не получила до сих пор доказательства. При этом выводы эмпирических 
исследований о соответствии правилу «ранг - размер» зависят, во-первых, от того, какие единицы анализа используются (города или городские агломерации), и, во-вторых, от определения города, используемого в официальной статистике. Простота и некоторая универсальность закона Ципфа являются свойствами, которые привлекают исследователей, однако выявление отклонений от этого правила не может трактоваться как свидетельство дефектов в городской системе страны и неэффективности механизмов ее формирования.

Поэтому отклонение от закона Ципфа нельзя считать веским основанием для практических решений в отношении управления развитием урбанистической системы. Хотя именно на эту закономерность ссылаются, когда высказываются рекомендации о политике поддержки развития крупных городов и агломераций в России.

\section{Литература}

1. От экономики переходного периода к экономике развития. Меморандум об экономическом положении Российской Федерации. Всемирный банк, 2005.

2. Региональное развитие и региональная политика России в переходный период / Ред. С.С. Артоболевский, О.Б. Глезер. - М.: Издательство МГТУ им. Н. Э. Баумана,2011.

3. Alperovich $G$. The Size Distribution of Cities. On the Empirical Validity of the Rank-Size Rule // Journal of Urban Economics. - 1984. - Vol. 16. P. 232-239.

4. Clayton E., Richardson T. Soviet control of city size // Economic Development and Cultural Change. - 1989. - Vol. 38. - P. 155-165.

5. Cordoba J. - C. On the distribution of city sizes //Journal of Urban Economics. - 2008. - Vol. 63. - P. 177-197.

6. Gabaix X. Zipf's Law for Cities: An Explanation // Quarterly Journal of Economics. - 1999. - Vol. 114. - P. 739-767.

7. Gaddy C. G., Hill F. The Siberian Curse: How Communist Planners Left Russia Out in the Cold. 2003. Brookings Institution Press: Washington, D.C. 8. Gang I. N., Stuart R. C. Mobility where mobility is illegal: Internal migration and city growth in the Soviet Union // Journal of Population Economics. - 1999. - Vol. 12. - P. 117-134.

9. Rastvortseva S., Manaeva I. Zipf's Law Appearance in the Russian Cities // Regional Science Inquiry. - 2016. - Vol. 1. - P. 51-59. 